\title{
DERECHOEIECTORAL
}

\section{Control de constitucionalidad de las elecciones en Eslovaquia}

Marek Domin

https://doi.org/10.35242/RDE $202131 \quad 14$

\section{Nota del Consejo Editorial}

Recepción: 29 de setiembre de 2020.

Revisión, corrección y aprobación: 11 de diciembre de 2020.

Resumen: El artículo describe el funcionamiento básico del control de constitucionalidad de las elecciones en la República Eslovaca en el contexto de la propuesta de la primera reforma fundamental en más de un cuarto de siglo. El contenido del artículo se compone de la competencia del tribunal para controlar la constitucionalidad de las elecciones, los procedimientos ante el tribunal, las formas en que el tribunal puede intervenir en los resultados de las elecciones y los requisitos previos para dicha intervención judicial. El artículo también incluye una breve reseña estadística de las actividades de toma de decisiones del Tribunal Constitucional de la República Eslovaca en asuntos electorales desde 1993, cuando se establecieron tanto la República Eslovaca como su Tribunal Constitucional.

Palabras clave: Elecciones / Sistemas electorales /Control de constitucionalidad / Reforma judicial / Justicia electoral / Jurisdicción electoral / Tribunal Constitucional / República Eslovaca.

Abstract: In the context of the first proposal of fundamental reform in more than a quarter of a century, the article describes the basic functioning of judicial review of the constitutionality of elections in the Slovak Republic. The content of the paper is formed, in particular, by the jurisdiction of the court to review the constitutionality of elections, the proceedings before the court, the ways in which the court can intervene in the results of the elections and the requirements for such judicial intervention. The article also includes a brief statistical overview of the decision-making activity of the Constitutional Court of the Slovak Republic in electoral matters since 1993 when both the Slovak Republic and its Constitutional Court were established.

Key Words: Elections / Electoral systems / Control of Constitutionality / Judicial reform / Electoral justice / Constitutional Tribunal / Republic of Slovakia.

\footnotetext{
* Eslovaco, abogado, correo marek.domin@flaw.uniba.sk. Profesor de Derecho Constitucional y subjefe del Departamento de Derecho Constitucional de la Universidad Comenius (Comenius University) de Bratislava (Eslovaquia). Especialista en derecho electoral y autor de los comentarios de dos leyes electorales de la República Eslovaca. En 2019 y 2020 fue consultor de la misión de observación electoral de la OSCE en Eslovaquia y en 2020 fue nombrado miembro de la comisión del Ministerio del Interior de la República Eslovaca que se ocupará de las posibilidades de introducir el voto electrónico en Eslovaquia.
} 


\section{DERECHO ELECTORAL}

\section{INTRODUCCIÓN}

Una de las tareas básicas del poder judicial en un Estado democrático de derecho es supervisar la constitucionalidad y legalidad de las elecciones, que son un requisito previo para el funcionamiento de la democracia representativa. Esto, naturalmente, también se aplica en la República Eslovaca.

El poder judicial en Eslovaquia lleva mucho tiempo en el punto de mira de profesionales y también de la opinión pública, desafortunadamente, no por las mejores razones. La confianza de la opinión pública eslovaca en los tribunales ha sido durante mucho tiempo muy baja. Esta confianza descendió mucho más a principios del año 2020 coincidiendo con el comienzo del enjuiciamiento criminal de trece jueces, incluido el vicepresidente del Tribunal Supremo, sospechosos de estar vinculados a delitos graves. El Ministerio de Justicia de la República Eslovaca respondió a la situación grave poco favorable con una propuesta de reforma del poder judicial, que incluye no solo una enmienda a la Constitución, sino también cambios en más de 20 leyes.

A pesar de que se esté prestando la mayor atención a las propuestas de cambios en la composición del Consejo Judicial ${ }^{1}$, la abolición de la inmunidad de los jueces, la jubilación automática de los jueces después de alcanzar cierta edad o a los cambios en el método de selección de los jueces del Tribunal Constitucional, la propuesta de reforma también incluye cambios en la justicia electoral. Se trata, concretamente, de dos cambios fundamentales. El primero consiste en la transferencia de la agenda de control de constitucionalidad de las elecciones del Tribunal Constitucional al nuevo Tribunal Administrativo Supremo; el segundo se centra en la introducción del sistema de dos instancias judiciales, lo que se aplica en el caso de decidir sobre propuestas relativas a determinados tipos de elecciones. De acuerdo con la intención original del Ministerio, dichos cambios deberían ser efectivos a partir del 1 de julio de 2021. La poca opinión pública eslovaca presta a los cambios en la justicia electoral es desproporcionada con respecto a la importancia de ese tipo de justicia

\footnotetext{
${ }^{1}$ El Consejo Judicial es un órgano de legitimidad del poder judicial. En particular, el Consejo Judicial garantiza la selección de candidatos a jueces para ser presentados al presidente de la República para su nombramiento. Este órgano también decide sobre las solicitudes de destitución de jueces. La mitad de los miembros del Consejo Judicial son jueces elegidos entre todos los jueces del país, tres miembros son nombrados por el Consejo Nacional de la República Eslovaca, tres por el Gobierno de la República y tres por el presidente de la República.
} 


\section{DERECHO ELECTORAL}

para el carácter democrático del país. El propósito del control judicial de la constitucionalidad de las elecciones es verificar si el poder público se ha restablecido de conformidad con la Constitución y las leyes (Drgonec, 2012 , p. 244) y, en caso contrario, corregir la posible inconstitucionalidad o ilegalidad de las elecciones y así asegurar la libre competencia de las fuerzas políticas.

El objetivo de este artículo es presentar brevemente al lector extranjero hispanohablante la justicia electoral en la República Eslovaca, especialmente el control de la constitucionalidad y legalidad de las elecciones. No solo nos centraremos en la competencia del tribunal o en las condiciones para presentar una petición que impugne la conducción de las elecciones, sino también en la forma en que el tribunal puede intervenir en los resultados de las elecciones y en las condiciones bajo las cuales puede hacerlo. La primera propuesta de reforma sustancial de la justicia electoral en Eslovaquia después del establecimiento de un Estado independiente en 1993 también ofrece espacio para la evaluación de su ejercicio hasta el presente. Por ello, el artículo también incluye un breve resumen de las actividades en la toma de decisiones del Tribunal Constitucional de la República Eslovaca en relación con el control de constitucionalidad de las elecciones.

\section{LAS ELECCIONES Y EL DERECHO ELECTORAL EN ESLOVAQUiA}

Con el debido respeto, es poco probable que el lector de Costa Rica u otro país latinoamericano hispanohablante conozca el tema de las elecciones y el derecho electoral en Eslovaquia, un pequeño país en el corazón de Europa. Por eso, antes de proceder a la descripción del control de constitucionalidad de las elecciones, es apropiado presentar al menos brevemente información básica sobre las elecciones y el derecho electoral en la República Eslovaca.

Respecto a la forma política del Estado, Eslovaquia puede describirse como una república parlamentaria (Bröstl, 2015, p. 178; Cibulka, 2014, p. 236 y Krošlák, 2016, p. 230) ${ }^{2}$. Las elecciones al parlamento, conocido

\footnotetext{
2 Debido a varias modificaciones en las relaciones mutuas entre el Parlamento, el Gobierno y el jefe de Estado, algunos expertos se desvían parcialmente de la afirmación de que la República Eslovaca todavía tenga una forma de gobierno parlamentaria. Sin embargo, estas opiniones son minoritarias, aunque sus partidarios más importantes incluyan, por ejemplo, a Ján Drgonec, catedrático de Derecho Constitucional y juez emérito del Tribunal Constitucional (véase Drgonec, 2018, p. 226 y siguientes).
} 


\section{DERECHO ELECTORAL}

como el Consejo Nacional de la República Eslovaca, son, por tanto, claves para la dirección política del Estado. La composición del Gobierno de la República, cuyos miembros son nombrados por el presidente de la República, también depende de la composición política del Consejo Nacional y de la confianza de sus diputados. El presidente de la República es el jefe de Estado y también es elegido directamente por los ciudadanos desde 1999, cuando la anterior elección parlamentaria fue sustituida por la mencionada. Mientras que en el caso de las elecciones al Consejo Nacional se aplica un sistema electoral proporcional, en el caso de las elecciones del presidente de la República se trata de un sistema electoral de mayoría absoluta (Giba, 2019, pp. 417 y 422). El sistema constitucional de la República Eslovaca también conoce otros tres tipos de elecciones. Desde la adhesión del país a la Unión Europea, que tuvo lugar en 2004, una parte de los miembros del Parlamento Europeo (PE) también es objeto de elección en Eslovaquia. El sistema electoral utilizado en las elecciones al PE es básicamente el mismo que se emplea en las elecciones al Consejo Nacional (Domin, 2020, p. 283). Finalmente, los órganos del autogobierno territorial también son elegidos directamente. El primer nivel de autogobierno territorial está representado por 2890 ciudades y municipios ${ }^{3}$, el segundo por 8 regiones autónomas. En ambos casos se eligen dos tipos de órganos del autogobierno, el alcalde y el presidente como órganos ejecutivos y la Asamblea como órgano legislativo. Las autoridades territoriales se eligen mediante un sistema electoral de mayoría relativa (Giba, 2019, p. 428). Todas las autoridades públicas mencionadas anteriormente son elegidas por un período de cuatro años. Una excepción es el cargo de presidente de la República, con una duración de cinco años.

La organización de las elecciones está garantizada por autoridades públicas especiales Ilamadas comisiones electorales. El sistema de comisiones electorales está encabezado por la Comisión Estatal de Elecciones, que cuenta con 14 miembros reemplazados siempre después de las elecciones al Consejo Nacional. Diez de estos miembros son nominados por partidos políticos parlamentarios ( 5 por los que formaron el Gobierno y 5 por los de oposición), los 4 miembros restantes son nombrados por el presidente del Tribunal Constitucional, el presidente del Tribunal Supremo (del Tribunal Administrativo Supremo, después de una

\footnotetext{
${ }^{3}$ La capital de la República Eslovaca, Bratislava, y la segunda ciudad más grande, Košice, tienen dos niveles del autogobierno con sus propios órganos. El nivel inferior consta de distritos urbanos, el nivel superior de la ciudad en su conjunto.
} 


\section{DERECHO ELECTORAL}

posible aprobación de la reforma), el presidente de la Oficina Superior de Control y por el fiscal general. Además de la Comisión Estatal de Elecciones, también hay comisiones electorales más bajas, cuyo sistema difiere ligeramente en los distintos tipos de elecciones. Esas comisiones están formadas por personas delegadas por los partidos políticos que han presentado una lista de candidatos.

La fuente fundamental de todas las normas que rigen las elecciones y el derecho electoral es, por supuesto, la Constitución de la República Eslovaca (en lo sucesivo, la "Constitución"). Sin embargo, la Constitución contiene solo los principios básicos del derecho electoral (el sufragio universal, igualitario, directo y secreto), el requisito de elecciones periódicas y las reglas básicas de los sistemas electorales. Se incluyen más detalles principalmente en dos leyes aprobadas conjuntamente en 2014, cuando se codificó el derecho electoral de la República Eslovaca ${ }^{4}$. La primera de esas leyes clave es la Ley sobre las condiciones para ejercer el derecho de voto, Ley $\mathrm{n}^{\circ} 180$ de 2014, la segunda es la Ley de campaña electoral, Ley n. 181 de 2014. Las reglas relativas al control de constitucionalidad de las elecciones también están incluidas en otras leyes especiales. La ley procesal decisiva actualmente en vigor es la Ley del Tribunal Constitucional de la República Eslovaca, Ley n. ${ }^{\circ} 314$ de 2018. De aprobarse la reforma propuesta, la norma procesal decisiva será el Código del procedimiento judicial administrativo, Ley n. ${ }^{\circ} 162$ de 2015.

No menos importante fuente del derecho electoral, especialmente en lo que respecta al control de constitucionalidad de las elecciones, es la jurisprudencia anterior del Tribunal Constitucional. Si bien estas decisiones son formalmente vinculantes solo inter partes, no hay duda de que el Tribunal Constitucional (o cualquiera que sea el tribunal competente en el futuro) las seguirá teniendo en cuenta también en los casos futuros. Al decidir sobre la constitucionalidad de las elecciones, los tribunales eslovacos también tienen en cuenta las decisiones del Tribunal Europeo de Derechos Humanos (TEDH), ya que la República Eslovaca es miembro del Consejo de Europa. El propio Tribunal Constitucional suele citar decisiones de TEDH en sus propias decisiones.

\footnotetext{
${ }^{4}$ Antes de la codificación del derecho electoral, que tuvo lugar en 2014 , cada tipo de elecciones estaba regulado por una ley separada. Como estas leyes fueron aprobadas en diferentes períodos históricos, comenzando en 1990 y terminando en 2004, diferían considerablemente en contenido. Para más detalles sobre la historia del derecho electoral en Eslovaquía, veáse Domin (2017, pp. 137-151).
} 


\section{DERECHO ELECTORAL}

\section{Competencia DEL tRIBUNAL PARA EL CONTROL DE LA} CONSTITUCIONALIDAD DE LAS ELECCIONES

El poder judicial de la República Eslovaca consiste en dos sistemas separados. El primero está formado por el Tribunal Constitucional (TC) ${ }^{5}$, el segundo por tres niveles de tribunales generales, encabezados por el Tribunal Supremo. Si se aprueba la reforma propuesta, la segunda "cabeza" del sistema de los tribunales generales será el Tribunal Administrativo Supremo (TAS). La primera instancia dentro del sistema de tribunales generales consta de 54 tribunales de distrito, la segunda instancia de ocho tribunales regionales. El Tribunal Penal Especializado también tiene el rango de un tribunal regional ${ }^{6}$.

Como ya hemos indicado en la introducción del artículo, la enmienda a la Constitución de la República Eslovaca propuesta en el verano de 2020 tiene intención de cambiar fundamentalmente la competencia del tribunal para controlar la constitucionalidad de las elecciones. Antes de la posible aprobación de esta enmienda, de conformidad con el art. 129 párr. 2.0 de la Constitución, el Tribunal Constitucional es competente para el control de constitucionalidad. Sin embargo, después de la posible aprobación de la reforma propuesta, a partir de julio de 2021, la competencia de controlar la constitucionalidad de las elecciones, de acuerdo con la disposición nueva del art. 142 párr. 2. ${ }^{\circ}$ de la Constitución, pasará al nuevo Tribunal Administrativo Supremo.

El TC (en el caso de la aprobación de la reforma propuesta, el TAS) tiene el poder de decidir sobre la constitucionalidad de todo tipo de elecciones. No se trata solo de elecciones nacionales, es decir, las elecciones al Consejo Nacional, elecciones presidenciales y elecciones al PE, sino también elecciones a los órganos de ambos niveles de autogobierno territorial, que tienen carácter regional. Por lo tanto, podemos preguntarnos si no sería más apropiado atribuir a los tribunales regionales la competencia del control de constitucionalidad de las elecciones a los

\footnotetext{
5 La competencia del TC incluye, por ejemplo, decidir sobre la conformidad de las normas legales, la interpretación de la Constitución en caso de controversias entre órganos del Estado o decidir sobre las denuncias de personas que objeten la violación de sus derechos y libertades fundamentales. El TC también decide sobre la acusación del presidente de la República por traición o violación intencional de la Constitución.

${ }^{6}$ Con la excepción del Tribunal Penal Especializado (y el TAS en el futuro), en Eslovaquia no se han establecido tribunales especializados. Los tribunales de distrito, los tribunales regionales y el Tribunal Supremo tienen jurisdicción general (asuntos civiles, penales y administrativos). Sin embargo, algunos tribunales de distrito también llevan a cabo una agenda especial. Hasta 2009, también hubo 4 tribunales militares en Eslovaquia (3 de primera instancia y 1 de la segunda instancia). Empero, todos los tribunales militares fueron abolidos y sus competencias se transfirieron a los tribunales generales.
} 


\section{DERECHO ELECTORAL}

órganos del autogobierno territorial. Como también expondremos en la penúltima parte de este artículo, el mayor número de denuncias que objetan la constitucionalidad de las elecciones se refiere claramente a las elecciones a los órganos del autogobierno territorial, específicamente las elecciones a los órganos de ciudades y municipios.

Es posible que el cambio de tribunal competente vaya a afectar la conformación del órgano que decidirá sobre la constitucionalidad de las elecciones. Mientras que el TC resuelve los asuntos electorales en una sesión plenaria compuesta por todos sus jueces (13), el TAS decidiría en un senado compuesto por 5 miembros.

La transferencia de la competencia del control de constitucionalidad de las elecciones del TC al nuevo TAS, pensada en la reforma propuesta en el verano de 2020, no es accidental. Los jueces del TC habían señalado durante mucho tiempo que el TC tenía un número relativamente grande de competencias y que sería apropiado considerar transferir algunas de ellas a otros órganos judiciales. La agenda electoral se mencionaba con mayor frecuencia. El motivo de la elección de esta agenda fue, entre otras cosas, que el Tribunal Administrativo Supremo decidía sobre asuntos electorales también en la vecina República Checa, la cual es históricamente, culturalmente y legalmente muy cercana a Eslovaquia. Otro argumento fue que las denuncias electorales sobrecargaban al TC también por su suministro considerablemente irregular. Como se desprende de la naturaleza del caso, el TC recibía estas denuncias solo en el tiempo inmediatamente posterior a la celebración de algunas de las elecciones.

Sin embargo, la reforma de la justicia electoral eslovaca propuesta en el 2020 no quiere excluir por completo al TC de controlar la constitucionalidad de las elecciones. Según la reforma propuesta, el TC debería obtener la competencia de decidir si la decisión del TAS sobre la constitucionalidad de las elecciones se ajustaba a la Constitución o a las leyes. Tal solución crearía el control de constitucionalidad de las elecciones en forma de dos instancias. Según la situación legal vigente en 2020, la decisión del TC sobre la denuncia electoral no podía ser revisada por ningún otro tribunal.

Empero, es importante decir que la posibilidad de que el TC revise la decisión del TAS, según la reforma propuesta, solo se aplicaría a categorías seleccionadas de elecciones. En concreto, se trata de las 


\section{DERECHO ELECTORAL}

elecciones al Consejo Nacional, las elecciones presidenciales y las elecciones al PE. El memorando explicativo de la enmienda a la Constitución justifica la selección de dichos tipos de elecciones al afirmar que las elecciones al Consejo Nacional como órgano constituyente y legislativo, así como las elecciones del presidente de la República, son una cuestión tan democráticamente sensible que es aconsejable mantener la supervisión del TC sobre la decisión del TAS.

\section{INICIACIÓN Y DESARROLLO DEL PROCEDIMIENTO ANTE EL TRIBUNAL}

Como es habitual en otros procedimientos judiciales que examinan los resultados de las elecciones, el procedimiento ante el Tribunal Constitucional sobre la constitucionalidad de las elecciones se rige por el principio de disposición. Así, el procedimiento no puede ser iniciado por el propio TC, sino que debe ser iniciado por uno de los sujetos activamente legitimados mediante una denuncia electoral. La Ley del Tribunal Constitucional de la República Eslovaca, que regula los detalles procesales relacionados con el control de constitucionalidad de las elecciones, contiene un cálculo exhaustivo de estos sujetos activamente legitimados. Por tanto, una denuncia presentada por otra entidad no produciría efectos legales relevantes.

Las entidades autorizadas para iniciar el procedimiento de control de constitucionalidad de las elecciones varían según el tipo de elección. En el caso de elecciones al Consejo Nacional y elecciones al PE, sólo (1) los partidos políticos y (2) las coaliciones de partidos políticos que hayan presentado una lista válida de candidatos podrán interponer una denuncia. Por tanto, la constitucionalidad de las elecciones parlamentarias no puede ser impugnada, por ejemplo, por alguno de los candidatos o alguno de los votantes.

En el caso de las elecciones presidenciales, las entidades legitimadas son diferentes, debido al diferente sistema electoral. La denuncia puede ser interpuesta por (1) un candidato presidencial no electo que haya obtenido al menos el $5 \%$ de los votos válidos, por (2) un grupo de al menos 15 miembros del Consejo Nacional o por (3) una comisión de peticiones que represente a un grupo de ciudadanos. Las dos últimas entidades tienen que ser el grupo de diputados o comisión de peticiones que hayan presentado una propuesta válida de candidato presidencial. Además de las entidades antes mencionadas, (4) el fiscal 


\section{DERECHO ELECTORAL}

general también puede presentar una denuncia que impugne las elecciones del jefe de Estado. No obstante, se desconoce la razón por la que el fiscal general puede demandar en el caso de las elecciones presidenciales, pero no en el de las parlamentarias.

Finalmente, respecto de las elecciones a los órganos del autogobierno territorial, la ley prevé la posibilidad de entablar una denuncia por tres categorías de entidades: (1) un candidato no electo que haya obtenido al menos el $\mathbf{1 0} \%$ de los votos válidos en su circunscripción; (2) un partido político que haya presentado la lista válida de candidatos y (3) un grupo de votantes. Las elecciones a los órganos del autogobierno territorial son, por tanto, las únicas cuya constitucionalidad también puede ser cuestionada directamente por los votantes. Sin embargo, solo un grupo de al menos el $10 \%$ de los votantes de la circunscripción puede presentar una denuncia.

La regulación legal relativamente detallada del procedimiento de control de constitucionalidad de las elecciones ante el TC incluye, también, los requisitos de la denuncia electoral. Además de los requisitos generales, que incorporan, por ejemplo, la forma escrita de la denuncia y la identificación del demandante y del demandado, la denuncia debe contener la declaración del demandante sobre si impugna las elecciones en su conjunto o solo en una circunscripción concreta. El demandante también tiene que comprobar su legitimación para interponer la denuncia, indicar la legislación y sus disposiciones específicas que hayan sido infringidas en las elecciones, así como señalar las pruebas destinadas a probar dichas infracciones. La denuncia también debe incluir una moción sobre cómo el tribunal debe tratar los resultados de las elecciones. Para respetar el principio de seguridad jurídica, que forma parte del principio constitucional del Estado de derecho, una denuncia se debe interponer a más tardar 10 días después del anuncio de los resultados de las elecciones. Como las elecciones en Eslovaquia siempre se celebran los sábados y sus resultados se conocen los domingos, el plazo para presentar una denuncia se calculará a partir del lunes siguiente.

La ley también regula el transcurso del procedimiento con gran detalle. Es cierto que, incluso en el caso de una denuncia que impugne la inconstitucionalidad de las elecciones, el tribunal debe proceder de acuerdo con las reglas generales contenidas en La Ley del Tribunal Constitucional de la República Eslovaca, a menos que las disposiciones especiales dedicadas a la justicia electoral prevean un procedimiento 


\section{DERECHO EIECTORAL}

diferente. EI TC tiene derecho a llamar a testigos (la mayoría de las veces candidatos o miembros de comisiones electorales) y solicitar los documentos necesarios (especialmente las actas de las comisiones electorales). Para mantener el principio de seguridad jurídica, la ley también establece un plazo para que el tribunal decida. La decisión debe emitirse a más tardar 90 días después de la entrega de la denuncia. Sin embargo, si el TC aún no cumple con el plazo, no hay sanción por incumplimiento. En tal caso, el poder y la obligación de tomar la decisión sobre la denuncia permanecen.

Los procedimientos que impugnan la inconstitucionalidad de las elecciones pueden terminar de dos maneras diferentes. Si el TC considera que la denuncia es infundada, la desestimará. En caso contrario, emitirá una de las tres posibles decisiones a las que se dedica la siguiente parte del artículo.

EI TC está obligado no solo a anunciar la decisión emitida, sino también a entregarla a los participantes del procedimiento. Una decisión válida también se entrega al Consejo Nacional, al Ministerio del Interior de la República Eslovaca y al órgano cuyas elecciones están en juego (por ejemplo, el PE o uno de los municipios).

Si finalmente se aprueba la transferencia de la agenda del control de constitucionalidad de elecciones al nuevo TAS, según lo previsto en la reforma propuesta, en el caso de algunas elecciones, el TC tendrá la posibilidad de decidir sobre una propuesta de revisión de la decisión del TAS, que decidirá en primera instancia en lugar del TC. En tal caso, la decisión se vuelve válida solo por la emisión de la decisión de TC, o después de la expiración del límite de tiempo para presentar una solicitud de revisión. En el caso de otro tipo de elecciones, el procedimiento finaliza legalmente el día del anuncio de la decisión del TAS.

\section{Posibilidades de INTERVENCIÓN JUdicial EN LOS Resultados ELECTORALES}

Como se indicó anteriormente en el artículo, a menos que el TC desestime una denuncia que impugne la inconstitucionalidad de las elecciones, tiene tres opciones para decidir. Puede (1) declarar inválidas las elecciones impugnadas en su totalidad; puede (2) anular el resultado de las elecciones impugnadas o puede (3) anular la decisión de la comisión electoral y declarar al candidato debidamente electo. Sin embargo, estas 


\section{DERECHO ELECTORAL}

tres opciones no se pueden combinar (Tribunal Constitucional, 1999, Sentencia PL. ÚS 50/99).

La ley, ni la de antes de la reforma propuesta en 2020 ni la que es parte de esa reforma, establece cuándo el tribunal debe elegir cuál de las tres alternativas. La selección de un método específico de decisión depende de qué defectos electorales se identificaron en las elecciones impugnadas y cómo, por lo tanto, pueden subsanarse. Varios tipos de defectos electorales se elaboran con cierto detalle tanto en la jurisprudencia del TC como en la bibliografía de derecho constitucional eslovaca. Hay tres tipos básicos de defectos electorales: un error electoral (por ejemplo, votos contados incorrectamente); un delito electoral (por ejemplo, votos contados intencionalmente incorrectamente) e influencia inadmisible sobre el resultado electoral, que puede consistir en la violación de las reglas de la campaña electoral (Ĺalík, M. y Ĺalík, T. 2019, p. 472). Sin embargo, también pueden producirse violaciones de la constitucionalidad de las elecciones durante la fase preparatoria de las elecciones y antes del inicio de la campaña electoral. Estos pueden ser varios defectos relacionados, por ejemplo, con la compilación de listas de votantes (Orosz, Molek, Svák y Šimíček, 2016, p. 371).

La selección de una forma particular para la intervención del tribunal en los resultados de las elecciones depende, por tanto, de la naturaleza del defecto electoral que se produjo durante el proceso electoral. La declaración de invalidad de las elecciones entra en consideración especialmente si hubo una violación de la Constitución o la ley en la fase preparatoria de la elección, es decir, antes de la votación en sí (Ĺalík y Ĺalík, 2019, p. 475). Sin embargo, también es posible declarar las elecciones inválidas en caso de violación de la Constitución o la ley durante la fase electoral. No obstante, estos deben ser defectos electorales que no sean cuantificables. Se trata, por tanto, de defectos para los que no es posible determinar exactamente cuántos votos han sido afectados por esos defectos. Por el contrario, si se pueden cuantificar los defectos electorales, procede la intervención judicial en forma de anulación del resultado de las elecciones impugnadas o de la anulación de la decisión de la comisión electoral y declaratoria de elección del candidato debidamente electo. Una situación típica de lo último es un error electoral consistente en votos contados incorrectamente. Por ejemplo, si el tribunal determina que el mayor número de votos fue obtenido por un candidato diferente al que figura en el acta, anula la decisión de la comisión electoral y declara electo al 


\section{DERECHO EIECTORAL}

candidato que realmente recibió la mayor cantidad de votos después de eliminar el error electoral. Este procedimiento es posible en el caso de elecciones para las que se aplica un sistema electoral mayoritario, por ejemplo, en las elecciones de los órganos del autogobierno territorial.

La consecuencia necesaria de declarar las elecciones inválidas es la necesidad de su repetición. En tal caso, el presidente del Consejo Nacional tiene que anunciar nuevas elecciones. Por el contrario, en caso de que se anule la decisión de la comisión electoral, no será necesario repetir las elecciones en cuestión.

\section{Requisitos pRevios para la intervención JUdicial en los RESULTADOS ELECTORALES}

No toda violación de la Constitución o de la ley conduce a una injerencia judicial en los resultados electorales, ya consista en declarar las elecciones inválidas o en anular la decisión de la comisión electoral. Hay dos razones. La primera es que en las condiciones de Eslovaquia la llamada teoría de los defectos electorales absolutos no se aplica, algo que había sido reiteradamente confirmado en el pasado por el TC (por ejemplo, Resolución PL. ÚS 54/2018 del 16 de enero del 2019). Cada defecto electoral es, por tanto, de carácter relativo y su impacto en las conclusiones del tribunal también depende de otros factores. La segunda de las razones es bastante práctica. El proceso electoral, y no solo en Eslovaquia, es tan complejo que nos resulta muy difícil imaginar unas elecciones sin ninguna violación de la ley, ni siquiera de carácter menos grave.

El TC, al que la Constitución encomendó el control de constitucionalidad de las elecciones, al menos hasta los finales de junio de 2021, ha elaborado, en más de 25 años de actividad, reglas establecidas relativamente detalladas sobre cuándo debe llegar la intervención del poder judicial en los resultados electorales. En un Estado democrático, el tribunal debe proceder con moderación al evaluar la propuesta que cuestiona los resultados de las elecciones. La intervención del poder judicial en los resultados electorales que expresan la voluntad del electorado debe ser un último recurso. Por tanto, deben cumplirse los 


\section{DERECHO ELECTORAL}

El control de constitucionalidad de las elecciones en...

siguientes tres requisitos para que el tribunal intervenga en los resultados electorales (véase, también, L'alík y Lalík, 2019, p. 473)².

El primer requisito consiste en una violación de la Constitución o de la ley en el desarrollo del proceso electoral. El proceso electoral se ve en un sentido más amplio. No solo será relevante el incumplimiento de las reglas durante la votación, sino también el incumplimiento de las reglas relativas al reconteo de los votos o a los procesos previos a la votación, como las reglas de la campaña electoral. Sin embargo, el incumplimiento de las reglas también debe ser establecido de manera creíble por el demandante. No basta con reclamar una posible violación de la Constitución o de la ley.

El segundo requisito consiste en una relación directa entre la violación de la Constitución o de la ley, por un lado, y el resultado electoral en cuestión, por el otro. En palabras del TC, los resultados de las elecciones no pueden verse afectados si se acuerda que esos resultados no podrían verse afectados sustancialmente por el incumplimiento identificado de las reglas.

Por último, el tercer requisito, sin el cual el tribunal eslovaco no puede intervenir en los resultados de las elecciones, es una suficiente intensidad de la violación de la Constitución o la ley. Demostrar el cumplimiento de este requisito es lo más difícil en la práctica. Debe ser un incumplimiento de las reglas que justifique la conclusión de que, si no se hubiera dado ese incumplimiento, los resultados de las elecciones habrían sido diferentes. Por tanto, la intensidad requerida debe cuestionar que los resultados electorales, también logrados por la violación de la Constitución o de la ley, constituyen la voluntad real de los votantes (veáse, por ejemplo, Sentencia PL. ÚS 11/2011 del 9 de marzo del 2011). Por tanto, la violación de la Constitución o la ley debe ser grave o reiterada. Sin embargo, la intensidad de la violación debe evaluarse en relación con el tipo de elecciones que se examinan (Drgonec, 2012, p. 250). La violación que es insuficiente en el caso de las elecciones al Consejo Nacional puede ser suficiente para la intervención judicial en los resultados de las elecciones a los órganos del autogobierno territorial.

\footnotetext{
7 Los tres requisitos que presuponen la injerencia judicial en los resultados electorales se enfatizan repetidamente en un gran número de decisiones del TC. Consulte, por ejemplo, Resolución PL. ÚS 62/2014 del 25 de febrero de 2015.
} 


\section{DERECHO EIECTORAL}

Para ilustrar la intensidad de la violación de la Constitución o de la ley que se necesita para la intervención judicial, vamos a dar algunos ejemplos. En el pasado, el TC declaró inválidas las elecciones en uno de los municipios eslovacos, porque uno de los candidatos a la función de alcalde estaba realizando una campaña electoral en un momento en que la ley lo prohibía. A pesar de que la campaña electoral se llevó a cabo solo en relación con seis votantes, la intensidad de la violación de la ley fue suficiente, ya que la diferencia entre el ganador de las elecciones y el segundo candidato en el orden fue tan solo de cinco votos (Sentencia PL. ÚS $18 / 7$ del 6 de febrero del 2008). Otro ejemplo son las elecciones de diputados de la Asamblea Municipal, declaradas inválidas porque uno de los diputados electos fue condenado válidamente por un delito intencionado, lo que obstaculiza la candidatura (TC, 2019c, Sentencia PL. ÚS 1/2019).

El requisito de la mínima intensidad necesaria de violación de la Constitución o de la ley tiene su importancia en el control de constitucionalidad de las elecciones en la República Eslovaca. Si no se exigiera una cierta intensidad mínima de incumplimiento de las normas, se podría abusar del control judicial de constitucionalidad de las elecciones. De hecho, algunos de los candidatos podrían violar deliberadamente las reglas de la campaña electoral, para preparar así una posible denuncia contra los resultados electorales si no estuvieran satisfechos con ellos (Balog, 2016, p. 114).

A pesar de la jurisprudencia relativamente bien establecida, la cual elabora los requisitos mencionados que permiten la intervención judicial en los resultados electorales, el TC (el TAS, después de la posible aprobación de la reforma) aborda cada caso de la impugnación de inconstitucionalidad de las elecciones de forma individual y teniendo en cuenta el propósito y el significado de la legislación electoral (veáse, por ejemplo, Resolución PL. ÚS 3/2013).

\section{CONTROL DE CONSTITUCIONALIDAD DE LAS ELECCIONES EN NÚMEROS}

Como indicamos en la introducción, la propuesta de la reforma de la justicia electoral eslovaca en 2020, que llega después de más de 25 años de funcionamiento, representa una buena oportunidad para una breve evaluación. 


\section{DERECHO ELECTORAL}

En los primeros 20 años (del 1 de enero de 1993 al 31 de agosto de 2013), el TC, como tribunal que dictaminó sobre la constitucionalidad de las elecciones en Eslovaquia, recibió un total de 488 denuncias electorales. Se trataba de todo tipo de elecciones, pero la gran mayoría de ellas eran elecciones a los órganos del autogobierno de ciudades y municipios (446, más del $91 \%)$. En segundo y tercer lugar se ubicaron las elecciones al Consejo Nacional (29, casi el $6 \%$ ) y las elecciones a los órganos del autogobierno de las regiones autónomas (9, casi el $2 \%$ ). Las elecciones presidenciales y europeas fueron objeto de un mínimo de denuncias ( 3 y 1 , respectivamente) (Tribunal Constitucional de la República Eslovaca, 2013b).

El enorme predominio de las denuncias electorales relativas a las elecciones a los órganos del autogobierno de las ciudades y municipios también se reflejó en el número de esas denuncias que finalmente llevaron a la intervención del tribunal en los resultados electorales. En los primeros 20 años, el TC no cumplió con ninguna de las denuncias relativas a las elecciones al Consejo Nacional, elecciones del presidente de la República, elecciones al PE y elecciones a los órganos de las regiones autónomas. EI TC solo cumplió 43 denuncias relativas a elecciones a los órganos de ciudades y municipios, que representaron más del $9 \%$ de todas las denuncias relativas a este tipo de elecciones. En estos 43 casos, el TC encontró una violación de la Constitución o de la ley que cumplía con los requisitos previos antes mencionados para la intervención del poder judicial en los resultados electorales. Estas cifras confirman que la intensidad del incumplimiento de las reglas exigida por el TC para intervenir en los resultados electorales fue realmente alta.

Para los próximos siete años (del 1 de septiembre de 2013 al 31 de julio de 2020) de la ejecución de la justicia electoral, las estadísticas oficiales aún no están disponibles, pero siguiendo los datos disponibles en el sitio web del TC, se pueden encontrar al menos 197 denuncias electorales más. Incluso en este período, claramente el mayor número de denuncias se refería a las elecciones a los órganos del autogobierno de ciudades y municipios (175, más del $88 \%$ ) y solo en el caso de este tipo de elecciones el TC se permitió intervenir en resultados electorales ${ }^{8}$.

\footnotetext{
8 Para más detalles, se pueden consultar los siguientes documentos del TC: Tribunal Constitucional de la República Eslovaca (2019, 2020a, 2020b, 2020c y 2020d).
} 


\section{DERECHO EIECTORAL}

Las denuncias electorales relativas a las elecciones del presidente de la República en 2019 y a las elecciones al Consejo Nacional en 2020 fueron monitoreadas particularmente de cerca por expertos legales y por la opinión pública. Incluso en esos casos, el TC no se atrevió a intervenir en los resultados electorales. Por último, una posible intervención en los resultados de las elecciones parlamentarias, teniendo en cuenta la forma de gobierno parlamentaria aplicada en la República Eslovaca, provocaría sin duda una considerable crisis política. También sería problemático si el tribunal interviniera en los resultados electorales después de que los diputados electos ocuparan sus escaños. Lo mismo fue, también, el caso de las elecciones parlamentarias de 2020 donde el TC resolvió una denuncia de una coalición de dos partidos políticos, que obtuvo más votos que los otros partidos políticos los cuales lograron los escaños parlamentarios, pero, debido a las reglas existentes ${ }^{9}$, no se le abrió camino hasta el parlamento. Finalmente, la denuncia de esa coalición fue rechazada por el TC.

\section{CONCLUSiones}

En el artículo hemos intentado abordar brevemente el funcionamiento del control judicial de constitucionalidad de las elecciones en la República Eslovaca. Además de su competencia y del procedimiento ante el tribunal en sí, también hemos prestado atención a la forma en que este puede interferir en los resultados de las elecciones, incluidos los requisitos para hacerlo de acuerdo con su propia jurisprudencia establecida. El artículo igualmente incluye un resumen de las actividades de toma de decisiones del TC en materia electoral hasta la fecha.

Según las estadísticas anteriores, el TC fue muy comedido en su posición como tribunal electoral. Decidió intervenir en los resultados de las elecciones solo en un número relativamente pequeño de casos que se le presentaron. El requisito previo decisivo para que el TC interviniera en los resultados electorales fue la demostración de una suficiente intensidad de violación de la Constitución o de la ley en el proceso electoral. Debió ser

\footnotetext{
9 Según el sistema electoral aplicado en las elecciones al Consejo Nacional, una lista de candidatos de un partido político debe obtener al menos el $5 \%$ del número total de votos válidos, de lo contrario no se procederá al proceso de asignación de escaños parlamentarios. En el caso de coaliciones compuestas por 2 o 3 partidos políticos, se requiere el $7 \%$ de los votos, en el caso de coaliciones compuestas por 4 o más partidos políticos, hasta el $10 \%$ de los votos. La coalición de 2 partidos políticos que presentó la denuncia obtuvo el 6,96 \% de los votos válidos.
} 


\section{DERECHO ELECTORAL}

de tal intensidad de inconstitucionalidad que cuestionó que los resultados de las elecciones representaran la voluntad real de los votantes eslovacos. El enfoque moderado del TC respecto a las denuncias electorales generalmente puede evaluarse positivamente, ya que en un Estado democrático los resultados de la competencia electoral ordinariamente deben decidirse en las salas de votación y no en los tribunales. La intervención judicial en los resultados electorales debe ser un medio de ultima ratio, que solo debe tener lugar si ha existido una inconstitucionalidad o ilegalidad genuinamente grave en el proceso electoral.

En verano de 2020, después de más de un cuarto de siglo de funcionamiento de la justicia electoral en la República Eslovaca, fue propuesta su reforma, que debe consistir, principalmente, en la transferencia de la competencia de toma de decisiones del TC al nuevo TAS. En particular, se espera que esta reforma, después de su aprobación, alivie al TC de la carga y la toma de decisiones más rápida relacionada con las presentaciones electorales.

En el momento de redactar este artículo, aún no estaba claro si se aprobaría la reforma propuesta. Si esto finalmente sucede, su éxito será verificado por las elecciones en el futuro, en particular en 2022, año en que Eslovaquia celebrará elecciones conjuntas para los órganos de ciudades y municipios y los órganos de las regiones autónomas, por primera vez. Como se desprende de los datos anotados anteriormente, son precisamente las elecciones a los órganos del autogobierno territorial (específicamente órganos de ciudades y municipios), en las que con mayor frecuencia se objeta la inconstitucionalidad.

\section{REFERENCIAS BIBLIOGRÁFICAS}

Balog, B. (2016). Právo na informácie vo volebnej kampani. Sloboda prejavu a jej limity. En Majerčák, T. (Ed.) Sloboda prejavu a jej limity-IV. ústavné dni, pp. 113-122. Košice: UPJS.

Bröstl, A. et al. (2015). Ústavné právo Slovenskej republiky. Plzeň: Aleš Čenek.

Cibulka, Ĺ. et al. (2014). Ústavné právo. Ústavný systém Slovenskej republiky. Bratislava: Univerzita Komenského v Bratislave, Právnická fakulta. 


\section{DERECHO EIECTORAL}

Domin, M. (2020). More votes but fewer parliamentary seats. Slovak consequences of delayed Brexit. The Lawyer Quarterly, (3), 279-292.

Domin, M. (2017). Volebné právo a volebné systémy. Bratislava: Wolters Kluwer.

Drgonec, J. (2018). Ústavné právo hmotné. Bratislava: C. H. Beck.

Drgonec, J. (2012). Konanie pred Ústavným súdom Slovenskej republiky. Šamorín: Heuréka.

Eslovaquia (1992). Constitución de la República Eslovaca. Ley n. 460.

Eslovaquia (2014). Ley sobre las condiciones para ejercer el derecho de voto. Ley $n .^{\circ} 180$.

Eslovaquia (2014). Ley de campaña electoral. Ley n. ${ }^{\circ} 181$.

Eslovaquia (2015). Código del procedimiento judicial administrativo. Ley n. ${ }^{\circ} 162$.

Eslovaquia (2018). Ley del Tribunal Constitucional de la República Eslovaca. Ley n. ${ }^{\circ} 314$.

Giba, M. et al. (2019). Ústavné právo. Bratislava: Wolters Kluwer.

Krošlák, D. et al. (2016). Ústavné právo. Bratislava: Wolters Kluwer.

Ĺalík, M. y Ĺalík, T. (2019). Zákon o Ústavnom súde Slovenskej republiky. Komentár. Bratislava: Wolters Kluwer.

Orosz, L., Molek, P., Svák, J. y Šimíček, V. (2016). Volebné právo a súdny prieskum volieb $v$ Českej republike a Slovenskej republike. Bratislava: C. H. Beck.

Tribunal Constitucional de la República Eslovaca (1999). Sentencia PL. ÚS 50/99 del 7 de marzo.

Tribunal Constitucional de la República Eslovaca (2008). Sentencia PL. ÚS 18/07 del 6 de febrero.

Tribunal Constitucional de la República Eslovaca (2011). Sentencia PL. ÚS 11/2011 del 9 de marzo.

Tribunal Constitucional de la República Eslovaca (2013a). Resolución PL. ÚS 3/2013 del 20 de febrero. 


\section{DERECHO EIECTORAL}

Tribunal Constitucional de la República Eslovaca (2013b). Štatistické údaje z rozhodovacej činnosti Ústavného súdu Slovenskej republiky vo volebných veciach podla čl. 129 ods. 2 Ústavy Slovenskej republiky v období rokov 1993-2013. Recuperado de https://www.ustavnysud.sk/documents/10182/992080/Volebn\%C3\%A9+\% C5\%A1tatistiky.pdf/fb672c1b-e171-4a6c-b2ab-c5f68edfcddf.

Tribunal Constitucional de la República Eslovaca (2015). Resolución PL. ÚS $62 / 2014$ del 25 de febrero.

Tribunal Constitutcional de la República Eslovaca (2019a). Konania vo volebných veciach. Volby do orgánov samosprávnych krajov. Recuperado de https://www.ustavnysud.sk/-/volby-do-organov-samospravnych-krajovu.

Tribunal Constitucional de la República Eslovaca (2019b). Sentencia PL. ÚS $54 / 2018$ del 16 de enero.

Tribunal Constitucional de la República Eslovaca (2019c). Sentencia PL. ÚS $1 / 2019$ del 23 de enero.

Tribunal Constitutcional de la República Eslovaca (2020a). Konania vo volebných veciach. Volby do Európskeho parlamentu. Recuperado de https://www.ustavnysud.sk/-/volby-do-europskeho-parlamentu.

Tribunal Constitutcional de la República Eslovaca (2020b). Konania vo volebných veciach. Volby do Národnej rady Slovenskej republiky. Recuperado de https://www.ustavnysud.sk/-/volby-do-nr-sr.

Tribunal Constitutcional de la República Eslovaca (2020c). Konania vo volebných veciach. Volby do orgánov samosprávy obcí. Recuperado de https://www.ustavnysud.sk/-/volby-do-organov-samospravy-obci.

Tribunal Constitutcional de la República Eslovaca (2020d). Konania vo volebných veciach. Volba prezidenta Slovenskej republiky. Recuperado de https://www.ustavnysud.sk/-/volba-prezidenta-slovenskej-republiky. 